\title{
Associated human factors for falls and fall-related injuries
}

\author{
K. Y. Z. Forrest \& J. M. Cali \\ Slipper Rock University of Pennsylvania, USA
}

\begin{abstract}
Purpose: Unintentional falls are common, especially among older adults. Many falls result in injuries, which lead to more medical conditions, disability, or even death. The current study evaluated the occurrence of falls and fall-related injuries, and their associated human factors among the population aged 45 years or older in the U.S.

Methods: The data from the 2006 Behavioral Risk Factor Surveillance System (BRFSS) were analyzed. The BRFSS is an ongoing data collection program that monitors risk factors for health problems in the adult U.S. population. The 2006 BRFSS included two questions about falls and injuries from falls that occurred in the past three months. The data were analyzed using the statistical program SUDAAN, which can account for the complex survey design and sample weight.

Results: Included in this study were 232,363 individuals who were aged 45 years or older and provided valid data on falls. Near $16 \%(n=38,976)$ of the study population reported at least one fall occurred in the past three months. All age groups had similar rates of falls with the highest occurrence seen among those aged 80 years or older. Females were more likely to fall than males $(16.7 \%$ vs. $14.5 \%$ ). The following factors increased the risk of falls: being unmarried, having a low income and education level, rural dwelling, no exercise, obesity, and poor health status (all p-values $<0.0001$ ). Of those who fell in the past three months, 34\% acquired injuries. Those of females, no college education, current smokers, obese individuals, and poor health were significantly more likely to sustain injuries from falls (all p-values $<0.05$ ).

Conclusions: To prevent falls, certain factors could be modified, such as regular exercise to manage weight, to improve muscle strength, gait and balance, and to enhance overall health condition.

Keywords: BRFSS, unintentional falls, older adults, socioeconomic status.
\end{abstract}




\section{Introduction}

Falls are among the most serious health concerns in older adults. As populations are aging in industrialized countries, fall incidences become even more common. Each year, one in every three individuals over the age of 65 years experience falls [1]. In the U.S., unintentional injury is the fifth leading cause of death in the general population, and falls are the second most common cause of unintentional injury across all age groups. In 2005, a total of 15,802 persons aged 65 years or older died as the consequence of injuries from falls [2]. Furthermore, the rate for fatal falls had increased $13.3 \%$ during 1993-2003 [3], due to the aging population.

Unintentional injuries from falls also frequently cause disabilities, fractures, and nursing-home admissions. The medical costs related to falls are enormous. Fall-related injuries in the U.S. cost more than $\$ 20$ billion each year, and by 2020 this cost is expected to reach $\$ 32.4$ billion [4]. Moreover, falls pose a significant negative impact on quality of life, as many people develop the fear of falling after falls and restrict their activities, resulting in further diminishing of their physical strength and increasing the likelihood of falling subsequently [5].

Studies show that certain factors contribute to falls $[6,7]$. These factors can be classified as intrinsic, extrinsic, and environmental. Intrinsic factors include lower extremity weakness, poor gait and balance, functional and cognitive impairment, visual deficits, etc. [8,9]. Use of certain medications and poor foot wares are some of the extrinsic factors. Examples of environmental factors are poor lighting, loose carpets, lack of bathroom safety equipment, etc [5].

Despite considerable research on falls, most of the studies focused on specific subpopulations [10], such as certain gender, old adults, nursing home patients, or people with certain diseases. Findings from large population-based data on falls and fall-related injuries are relatively scarce. The purpose of the current study was to evaluate fall occurrences and fall-related injuries and associated factors among both middle-aged and older adults in the general U.S. population by analyzing the data from the 2006 Behavioral Risk Factor Surveillance System (BRFSS) [11]. Because of the magnitude of the problem, fall-related death prevention is an objective in the U.S. Healthy People 2010 [12]. The specific goal is to reduce the number of deaths resulting from falls among those aged 65 or older to no more than 34.6 per 100,000 persons from the baseline of 38.4 per 100,000 persons. Understanding the factors that correlated with falls is the first necessary step for achieving the goal.

\section{Methods}

\subsection{Data sources}

The BRFSS is a collaborative project of the Centers for Disease Control and Prevention (CDC) and U.S. states and territories. The BRFSS, initiated in 1984, is an ongoing data collection program designed to measure behavioral risk 
factors in the U.S. adult population (18 years of age or older) living in households. The objective of the BRFSS is to monitor preventive health practices and risk behaviors that are linked to chronic diseases, injuries, and preventable infectious diseases in the adult population [11].

Data collection in the BRFSS is managed by state health departments with the guidelines provided by the CDC. A random sample of adults (one per household) is surveyed every year through a telephone interview. The data collected by state health departments are then transmitted to the CDC for processing at the national level. Edited BRFSS data files are available at the CDC's website as public domain data. The current study analyzed the 2006 BRFSS data. The Institutional Review Board (IRB) of the Centers for Disease Control and Prevention (CDC) approved the BRFSS.

\subsection{Measurements}

\subsubsection{Falls and fall-related injuries}

In the 2006 BRFSS, two unique questions were added to obtain information about falls and fall-related injuries among the study participants aged 45 years or older. The first question was: "In the past 3 months, how many times have you fallen"? Four responses were provided to this question: "number of times of falls", "none", "don't know", or "refused". Study participants with the responses of "don't know" or "refused" were excluded from this study (2.6\%). Among the study participants who had at least one fall in the past three months, a second question was asked: "How many of these falls caused an injury? (By an injury, we mean the fall caused you to limit your regular activities for at least a day or to go see a doctor)". The response for the second question was: "number of times of falls", "none", "don't know", or "refused". Those with the responses of "don't know", or "refused" were excluded from related analyses $(0.6 \%)$. Two binominal (yes/no) variables were created according to these two questions on whether or not any fall in the past three months and any injury from the fall(s) had occurred.

\subsubsection{Other measurements}

Age was categorized into nine 5-year age groups. Race was classified into White, Black, Hispanic, and other races. Annual family income was assessed as either less than $\$ 35,000$ or $\$ 35,000$ or more. Self-reported general health status recorded as excellent, very good, good, fair, and poor. Overweight was defined by body mass index (BMI) of 25 or above, and obesity, by BMI of 30 or above. Smoking status was categorized into current smokers and non-smokers. Heavy alcohol use was defined as adult men having more than two drinks per day and adult women having more than one drink per day. Information was also obtained concerning marital status, college education, and metropolitan classification.

\subsection{Statistical analysis}

Two statistical programs were used to analyze data in the current study. Since the BRFSS data are in SAS format, the statistical program SAS System for Windows (Release 8.2) (SAS Institute Inc. Cary, NC) was utilized for data 
management and variable examination, such as sorting data and recoding variables. Due to the nature of complex survey data from the BRFSS, statistical software SUDAAN (Release 9.0.1) (Research Triangle Institute, Research Triangle Park, NC) was used to analyze data, as SUDAAN can account for the complex multistage sample design and sample weigh.

The PROC CROSSTAB procedure in SUDAAN was utilized for univariate analysis, such as description of study population and assessment of bivariate associations. Fall and fall-related prevalence rates were calculated by dividing the number of persons with an occurrence by the total number of survey participants in the same group. Differences in prevalence rates were evaluated for statistical significance by the chi-square test, which is available in SUDAAN. Ninety-five percent confidence intervals $(95 \% \mathrm{CI})$ were provided for all prevalence rates. The PROC LOGISTIC procedure in SUDAAN was employed to identify independent correlates of falls or fall-related injuries in multivariate analyses. All analyses used weighted data to adjust for non-response so that the results were representative to the US population. These adjustments were made by applying weights in all analyses. Weights were provided by the CDC and available in the BRFSS data files.

\section{Results}

\subsection{Study population description}

Included in this study were 232,363 individuals who were aged 45 years or older and provided valid data on falls. About one third of the study population was aged 65 years or older, and 53.7\% were females. The majority of the study population was White (76.8\%), with $8.5 \%$ of Black, $9.3 \%$ of Hispanic, and $5.4 \%$ of other races. In this study population, $67.8 \%$ were married, $60.5 \%$ had a family annual income of $\$ 35,000$ or more, $58.4 \%$ received some college education, and $20.4 \%$ lived in rural areas. About two third of the study population were overweight or obese, and $6.8 \%$ reported a poor health status (Table 1 ).

\subsection{Falls}

In the study population, $15.7 \%(\mathrm{n}=38,976)$ individuals reported at least one fall occurred in the past three months. The average number of falls in the past three months among those who fell was 2.1. The risk of falls increased from age 45 through 59, then decreased till age 69, and increased again after age 70 . The highest fall occurrences were seen among those aged 80 years or older. Females had a higher prevalence rate of falls before age 65; however, the gender difference was inferior after age 65 (Figure1). Those who were unable to work or who were unemployed had a significantly higher prevalence rate of falls in the past three months (figure 2).

Univariate analyses showed that the following factors (Table 2) increased the risk of falls: being females, aged 80 years or older, White race, not currently 
Table 1: Characteristics of the study population.

\begin{tabular}{|c|c|}
\hline Characteristics & N (Weighted \%) \\
\hline $\begin{array}{l}\text { Gender } \\
\text { Male } \\
\text { Female } \\
\end{array}$ & $\begin{array}{c}87,721(46.3) \\
144,642(53.7)\end{array}$ \\
\hline $\begin{array}{l}\text { Age Distribution (yrs) } \\
\quad 45-64 \\
\geq 65 \\
\end{array}$ & $\begin{array}{c}142,084(66.4) \\
90,279(33.6) \\
\end{array}$ \\
\hline $\begin{array}{l}\text { Race } \\
\text { White } \\
\text { Black } \\
\text { Hispanic } \\
\text { Other }\end{array}$ & $\begin{array}{c}189,911(76.8) \\
16,609(8.5) \\
12,162(9.3) \\
10,951(5.4)\end{array}$ \\
\hline $\begin{array}{l}\text { Family Annual Income } \\
\quad<\$ 35,000 \\
\quad \geq \$ 35,000\end{array}$ & $\begin{array}{c}89,357(39.5) \\
107,138(60.5) \\
\end{array}$ \\
\hline $\begin{array}{l}\text { Employment Status } \\
\text { Employed } \\
\text { Unemployed } \\
\text { Homemaker } \\
\text { Retired } \\
\text { Unable to Work }\end{array}$ & $\begin{array}{c}107,473(50.3) \\
7,060(3.5) \\
16,011(7.1) \\
83,158(32.0) \\
17,430(7.1) \\
\end{array}$ \\
\hline $\begin{array}{l}\text { Any College Education } \\
\text { Yes } \\
\text { No }\end{array}$ & $\begin{array}{c}132,413(58.4) \\
99,374(41.6) \\
\end{array}$ \\
\hline $\begin{array}{l}\text { Residential Area } \\
\text { Metropolitan Area } \\
\text { Rural Area }\end{array}$ & $\begin{array}{c}149,723(79.6) \\
77,814(20.4)\end{array}$ \\
\hline $\begin{array}{l}\text { Marital Status } \\
\text { Yes } \\
\text { No } \\
\end{array}$ & $\begin{array}{l}129,817(67.8) \\
101,520(32.2)\end{array}$ \\
\hline $\begin{array}{l}\text { Current Smoking } \\
\text { Yes } \\
\text { No }\end{array}$ & $\begin{array}{c}37,971(16.4) \\
193,372(83.6)\end{array}$ \\
\hline $\begin{array}{l}\text { Heavy Alcohol Use } \\
\text { Yes } \\
\text { No } \\
\end{array}$ & $\begin{array}{c}9,330(4.2) \\
218,012(95.8) \\
\end{array}$ \\
\hline $\begin{array}{c}\text { Exercise } \\
\text { Yes } \\
\text { No }\end{array}$ & $\begin{array}{c}166,898(72.6) \\
65,170(27.4)\end{array}$ \\
\hline $\begin{array}{l}\text { Weight Status } \\
\text { Normal } \\
\text { Overweight } \\
\text { Obese }\end{array}$ & $\begin{array}{l}77,408(33.5) \\
84,759(39.3) \\
59,312(27.1)\end{array}$ \\
\hline $\begin{array}{l}\text { General Health Status } \\
\text { Excellent/Good } \\
\text { Fair } \\
\text { Poor }\end{array}$ & $\begin{array}{c}24,000(77.8) \\
35,833(15.4) \\
6,323(6.8)\end{array}$ \\
\hline
\end{tabular}


married, family annual income less than $\$ 35,000$, no college education, rural dwelling, currently smoking, heavy alcohol use, no exercise, obesity, and selfreported poor health status (all p-values $<0.0001$, except alcohol use). All these factors were also confirmed to be independently associated with falls in multivariate analyses (all p-values $<0.05$ ).

\subsection{Fall-related injuries}

Of those who fell in the past three months, $33.1 \%(n=12,980)$ sustained injuries. Figure 3 presents the prevalence rates of fall-related injuries in the past three months by age and gender. For all ages, females had a significantly higher risk of getting injuries from falls. The prevalence rate of fall-related injuries was highest among the youngest age group (45-49), then decreased till age 65, and increased afterwards. Among females, however, this rate decreased again for age 75 years or older. Those who were unable to work or who were unemployed had significantly higher prevalence rate of fall-related injuries in the past three months (Figure 4).

Those of the female gender, aged between 45 - 54, White race, unmarried, with a lower socioeconomic status, current smokers, no exercise, obese individuals, and poor health were significantly more likely to acquire injuries from falls (all p-values $<0.05$ ) (Table 3). Multivariate analyses revealed that both age groups of 45-54 and 70 or older, females, no college education, unable to work, currently smoking, obese, and with a poor health status were all independently associated with fall-related injuries (all p-values $<0.05$ ).

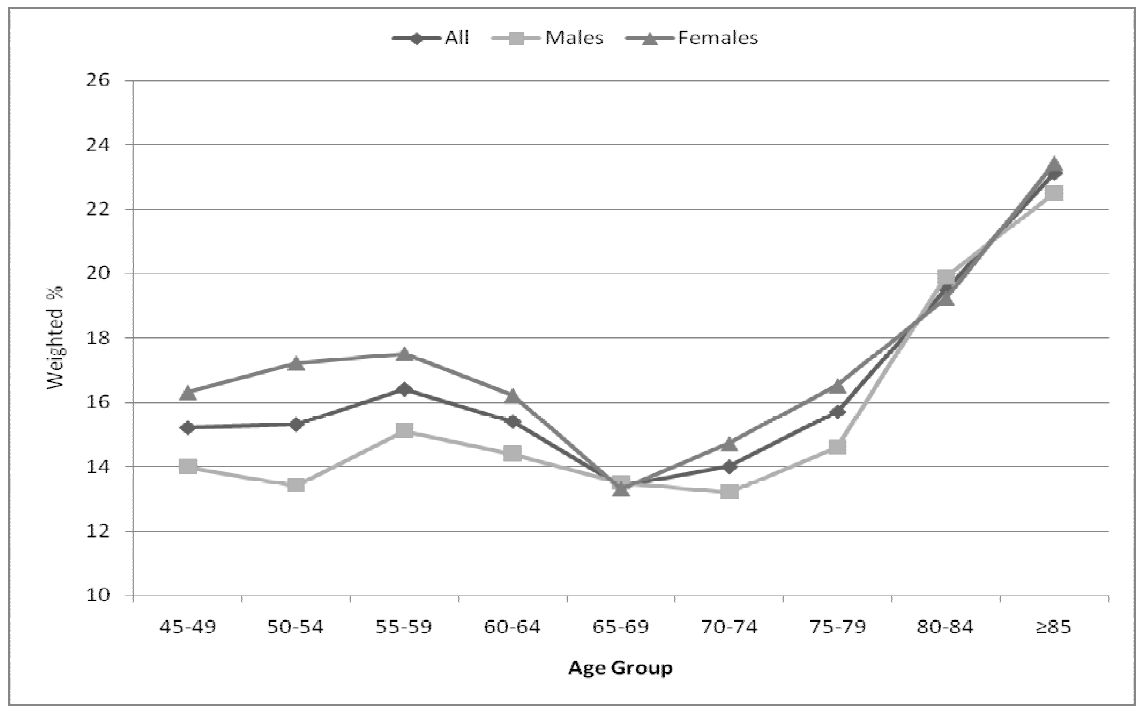

Figure 1: $\quad$ Prevalence rate of falls in the past three months by age and gender. 


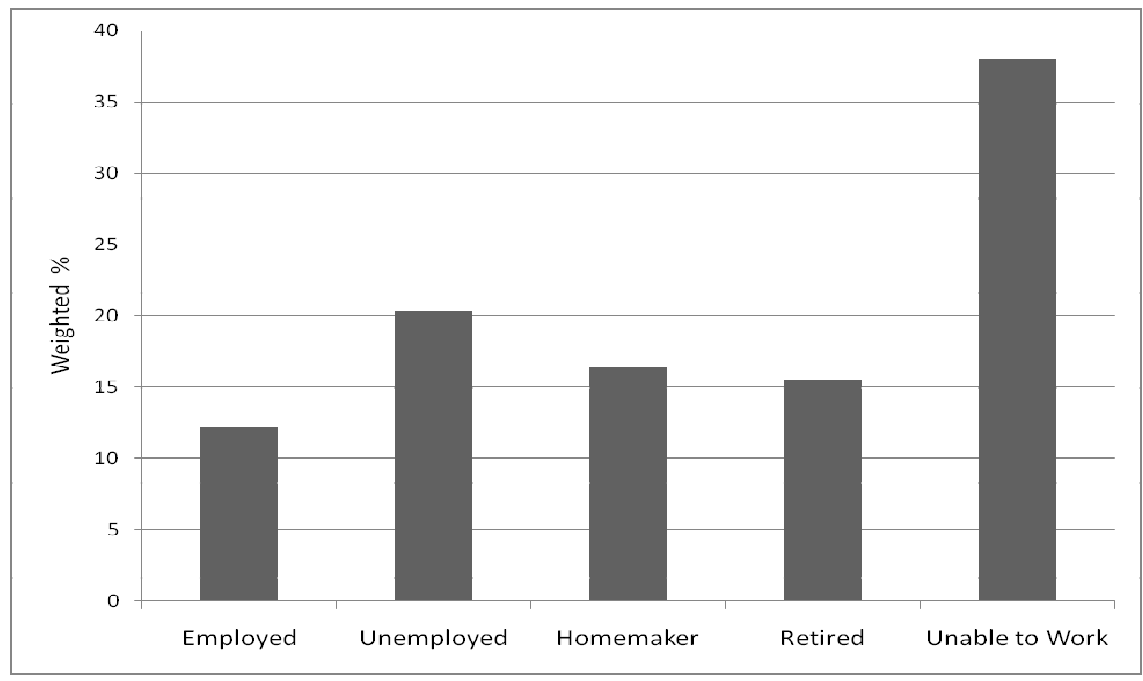

Figure 2: $\quad$ Prevalence rate of falls by employment status.

Table 2: $\quad$ Factors associated with falls in the past three months.

\begin{tabular}{|l|c|c|c|}
\hline \multirow{2}{*}{ Factors } & \multicolumn{2}{|c|}{$\begin{array}{c}\text { Any Fall in the Past Three Months } \\
\text { Weighted \% }\end{array}$} & \multirow{2}{*}{ P-value } \\
\cline { 2 - 3 } & $\begin{array}{c}\text { Yes } \\
(\mathrm{n}=38,976)\end{array}$ & $\begin{array}{c}\text { No } \\
(\mathrm{n}=193,387)\end{array}$ & \\
\hline Females & $57.2(56.2-58.3)$ & $53.1(52.6-53.5)$ & $<.0001$ \\
\hline Age $\geq 80$ Years & $10.8(9.9-11.7)$ & $7.6(7.3-7.9)$ & $<.0001$ \\
\hline White Race & $78.0(76.9-79.0)$ & $76.6(76.1-77.0)$ & 0.0163 \\
\hline Unmarried & $38.1(37.2-39.1)$ & $31.1(30.7-31.5)$ & $<.0001$ \\
\hline Income $<\$ 35,000$ & $49.2(48.1-50.4)$ & $37.7(37.2-38.2)$ & $<.0001$ \\
\hline Unable to Work & $17.3(16.5-18.1)$ & $5.2(5.0-5.4)$ & $<.0001$ \\
\hline No College Education & $44.4(43.4-45.5)$ & $41.1(40.6-41.5)$ & $<.0001$ \\
\hline Rural Dwelling & $23.3(22.6-24.0)$ & $19.9(19.6-20.1)$ & $<.0001$ \\
\hline Current Smokers & $19.5(18.7-20.3)$ & $15.8(15.5-16.2)$ & $<.0001$ \\
\hline Heavy Alcohol User & $4.7(4.2-5.1)$ & $4.1(3.9-4.3)$ & .0330 \\
\hline No Exercise & $34.2(33.3-35.2)$ & $26.2(25.8-26.6)$ & $<.0001$ \\
\hline Obese & $33.1(32.2-34.2)$ & $26.0(25.6-26.4)$ & $<.0001$ \\
\hline Fair/Poor Health Status & $37.8(36.2-39.6)$ & $19.3(18.7-19.8)$ & $<.0001$ \\
\hline
\end{tabular}




\section{Discussion}

This study analyzed the 2006 BRFSS data to examine fall occurrences and fallrelated injuries in the past three months and associated factors in the general U.S. population aged 45 years or older. The authors found that falls and fall-related injuries were not just common among the individuals over 65 years but also frequent among the middle-aged group before reaching 65 years. Additionally, the peak of fall-related injuries was seen between ages 45 to 54 years. This increased risk could be due to certain occupations. Since the BRFSS did not ask where falls occurred, it was unclear whether or not the reported falls were related to occupations. However, when evaluating fall and fall-related injury prevalence rates by employment status, those who were currently employed had the lowest rates, and those who were unable to work or unemployed had the highest rates. One possible explanation for this finding was that certain health problems that make people to ill to work or to be employed also put these people at a higher risk of falling. This finding provided an alert that prevention for falls should start earlier than senior years, as one in three falls among those aged 45 to 54 would result in an injury.

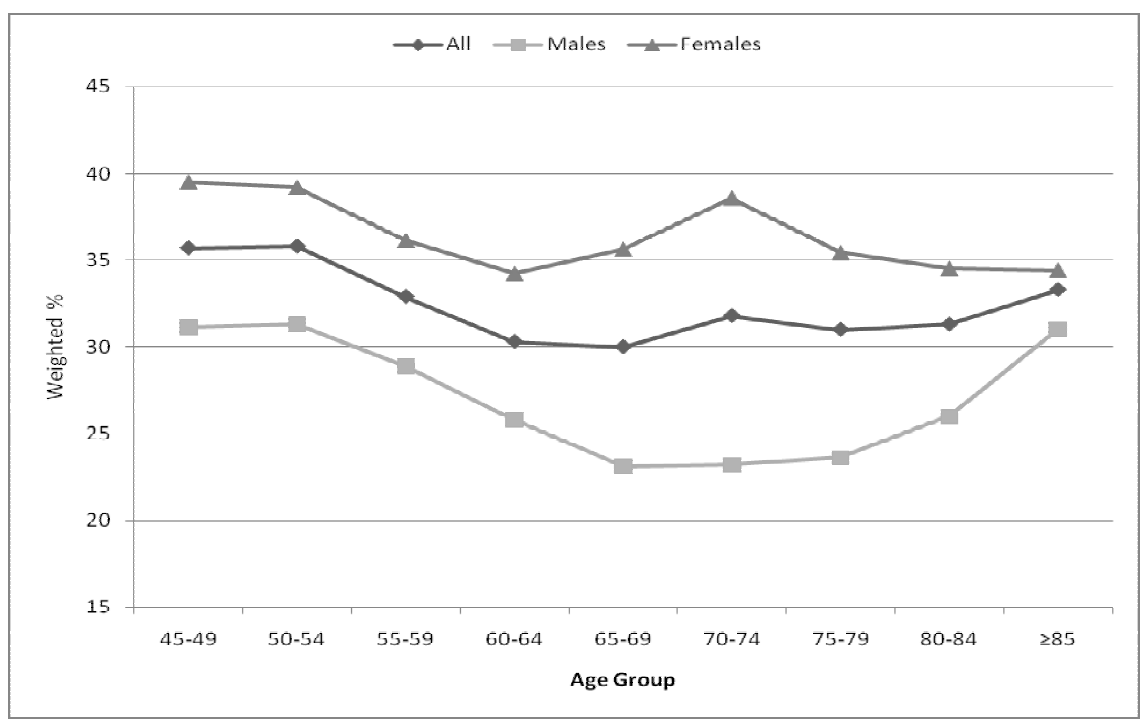

Figure 3: $\quad$ Prevalence rate of fall-related injuries in the past three months by age and gender.

Socioeconomic status was also shown to impact falls and fall-related injuries. The indirect impact of socioeconomic status on health is well evident [13]. A higher socioeconomic status indicates more knowledge (including health-related issues), likelihood of being physically active, good work environment, and better access to health care, and less chance of being a smoker and obese, both were significant risk factors for falls and fall-related injuries. 
Females usually had a higher risk of falls compared to males $[14,15]$. The current study confirms this phenomenon. However, the gender difference of falls was inconsequential for older adults aged 65 years or older, indicating prevention for falls should target older men as well. On the other hand, females were significantly more likely to sustain injuries from falls than males across all ages, which could be due to the factor that females have a lower bone mineral density than males in general.

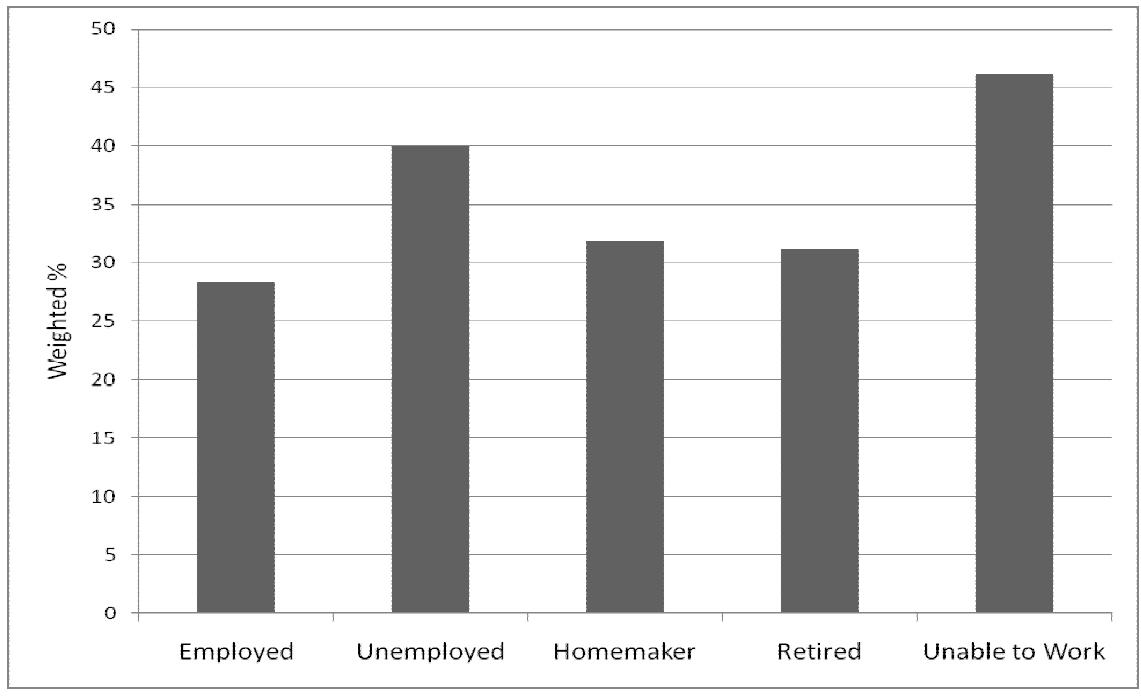

Figure 4: Prevalence rate of fall-related injuries by employment status.

Healthy life styles benefit good health in different ways, including preventing falls and fall-related injuries. The current study showed that exercise decreased the risk of falls and fall-related injuries, while obesity, smoking and heavy alcohol use increased the risk. Interestingly, marital status also had an influence on falls, although it is not clear why such an association exists.

The BRFSS is well designed and collects data from a very large sample to represent the U.S. population [11], which is the strength of this study. There are several limitations recognized in this study. First, the survey is based on noninstitutionalized populations and excludes persons residing elsewhere, such as nursing homes or long term care facilities. Thus, the rate of falls and fall-related injuries could be underestimated. Second, the BRFSS data were self-reported and recall bias was possible for both fall related information or other study variables. Third, as all survey designs, the temporal relationship between falls and some associated factors were unclear, for example, poor health could be the cause or the consequence of a fall.

In conclusion, this study found that falls were common among both males and females aged 45 years or older in the U.S. One in every three falls would result in an injury, which caused limitations to one's regular activities for 
Table 3: Factors associated with fall-related injuries in the past three months.

\begin{tabular}{|c|c|c|c|}
\hline \multirow[t]{2}{*}{ Factors } & \multicolumn{2}{|c|}{$\begin{array}{c}\text { Any Injury from Falls } \\
\%(95 \% \text { CI })\end{array}$} & \multirow[t]{2}{*}{ P-value } \\
\hline & $\begin{array}{c}\text { Yes } \\
(\mathrm{n}=12,980)\end{array}$ & $\begin{array}{c}\text { No } \\
(\mathrm{n}=25,749)\end{array}$ & \\
\hline Females & $63.8(62.0-65.6)$ & $53.9(52.7-55.2)$ & $<.0001$ \\
\hline Age $45-54$ & $40.5(37.3-43.8)$ & $36.0(34.0-38.0$ & .0080 \\
\hline White Race & $25.1(23.2-27.1)$ & $20.4(19.2-21.6)$ & .0017 \\
\hline Unmarried & $42.5(40.7-44.3)$ & $35.9(34.8-37.1)$ & $<.0001$ \\
\hline Income $<\$ 35,000$ & $56.0(54.0-58.0)$ & $45.8(44.4-47.2)$ & $<.0001$ \\
\hline Unable to Work & $23.9(22.3-25.6)$ & $13.9(13.0-14.8)$ & $<.0001$ \\
\hline No College Education & $46.2(44.4-48.1)$ & $43.4(42.2-44.6)$ & .0131 \\
\hline Rural Dwelling & $23.2(22.0-24.5)$ & $23.4(22.5-24.2)$ & .9803 \\
\hline Current Smokers & $22.7(21.1-24.2)$ & $17.9(17.0-18.9)$ & $<.0001$ \\
\hline Heavy Alcohol User & $4.2(3.5-5.1)$ & $4.9(4.3-5.5)$ & .2059 \\
\hline No Exercise & $39.6(37.9-41.5)$ & $31.4(30.3-32.6)$ & $<.0001$ \\
\hline Obese & $36.2(34.4-38.1)$ & $31.6(30.5-32.8)$ & .0001 \\
\hline Fair/Poor Health Status & $48.3(45.0-51.8)$ & $32.5(30.7-34.4)$ & $<.0001$ \\
\hline
\end{tabular}

at least a day or going see a doctor. The factors found to be associated with falls and fall-related injuries were age, gender, low income, lack of education, smoking, no exercise, obesity and poor health status. To prevent falls, certain factors could be modified, such as living a healthy lifestyle, including regular exercise to manage weight, to improve muscle strength, gait and balance, and to enhance overall health condition.

\section{References}

[1] Hausdorff, J.M., Fios, D.A. \& Edelberg, H.K., Gait variability and fall risk in community-living older adults: a 1-year prospective study. Arch Phys Med Rehabil, 82, pp.1050-56, 2001.

[2] CDC. Self-reported falls and fall-related injuries among persons aged $\geq 65$ years - United Sates, 2006. MMWR, 57, pp. 225-229, 2008.

[3] CDC. Fatalities and injuries from falls among older adults - United States, 1993-2003 and 2001-2005. MMWR, 55, pp. 1222-4, 2006.

[4] CDC \& Merck Institute of Aging and Health. The State of Aging and Health in America 2004. www.agingsociety.org/agingsociety/pdf/ SAHA_2004.pdf 
[5] American Geriatrics Society, British Geriatrics Society, and American Academy of Orthopaedic Surgeons Panel on Falls Prevention. Guideline for the prevention of falls in older persons. J Am Geriatr Soc, 49, pp. 664-72, 2001.

[6] Stevens, J.A., \& Sogolow, E.D. Gender differences for nonfatal unintentional fall related injuries among older adults. Injury Prev, 11, pp. 115, 2005.

[7] Berg, W.P., Alessio, H.M., Mills, E.M., \& Tong, C. Circumstances and consequences of falls in independent community-dwelling older adults. Age Ageing, 26, pp. 261, 1997.

[8] Stel, V.S., Smit, J.H., Pluijm, S.M., et al. Balance and mobility performance as treatable risk factors for recurrent falling in older persons. J Clin Epidemiol, 56, pp. 659-68, 2003.

[9] Moreland, J.D., Richardson, J.A., Goldsmith, C.H., et al. Muscle weakness and falls in older adults: a systematic review and meta-analysis. $\mathrm{J} \mathrm{Am}$ Geriatr Soc, 52, pp. 1121-9, 2004.

[10] Chan, B.K., Marshall, L.M., Winters. K.M., et al. Incident fall risk and physical activity and physical performance among older men: the Osteoporotic Fractures in Men Study. Am J Epidemiol, 165, pp. 696-703, 2007.

[11] BRFSS. www.cdc.gov/brfss/

[12] Healthy People 2010. www.healthypeople.gov

[13] Krieger, N., Rehkopf, D.H., Chen, J.T., Waterman, P.D., Marcelli, E., \& Kennedy, M. The fall and rise of US inequities in premature mortality: 1960-2002. PLoS Med, 5, pp. 227-41, 2008.

[14] O’Loughlin, J.L., Robitaille, Y., Biovin, J., \& Suissa, S. Incidence of and risk factors for falls and injurious falls among the community-dwelling elderly. Am J Epidemiol, 137, pp. 342, 1993.

[15] Sattin, R.W., Lambert Huber, D.A., DeVito, C.A., et al. The incidence of fall injury events among the elderly in a defined population. $\mathrm{Am} \mathrm{J}$ Epidemiol, 131, pp. 1028, 1990. 